\title{
Juventude, Vulnerabilidade Social e Exploração Sexual: um olhar a partir da articulação entre Saúde e Direitos Humanos
}

\section{Youth, Social Vulnerability and Sexual Exploitation: a look from articulation between Health and Human Rights}

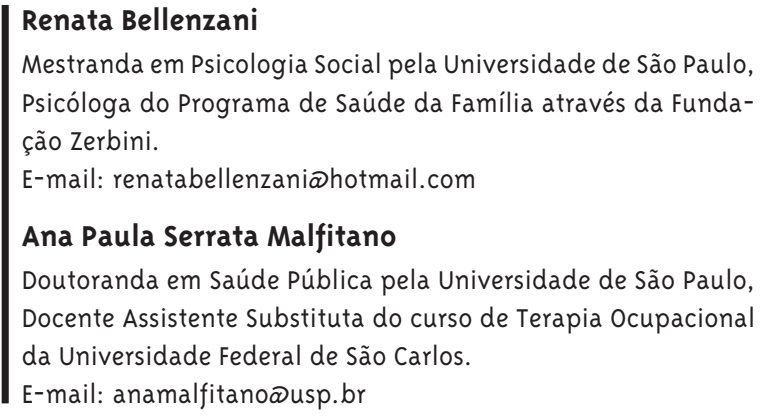

E-mail: anamalfitano®usp.br

\section{Resumo}

Este trabalho relata a experiência do projeto "Rotas recriadas: crianças e adolescentes livres da exploração sexual", que problematiza, a partir de uma perspectiva sociocultural, as formas de enfrentamento da exploração sexual comercial infanto-juvenil, em Campinas-SP. Com diferentes eixos de atuação, de caráter intersetorial e interdisciplinar, o projeto propõe o embasamento teórico e o desenvolvimento de ações-piloto, com o intuito de promover debate para a construção de uma política pública de enfrentamento dessa relevante temática. Apresentamos a experiência de um dos campos de intervenção, a área de saúde, por meio do trabalho com uma das populações-alvo deste projeto: crianças e adolescentes em situação de rua e exploração sexual comercial. Fundamentamo-nos na necessária articulação entre saúde e direitos humanos, uma vez que negligências e violações dos direitos podem resultar em conseqüências para a saúde. Buscamos a garantia dos direitos desta população, tão cerceada em vivenciá-los. Para atingir essa articulação atuamos a partir da técnica do Acompanhamento Terapêutico, como estratégia que propicia a junção entre necessidades coletivas e individuais, incluindo intervenções pautadas na promoção e na garantia de direitos. Utilizamo-nos de relatos de "cenas" de histórias de vida, sobre as quais objetivamos a diminuição das vulnerabilidades sociais vivenciadas, à luz do direito ao exercício pleno de direitos.

Palavras-chave: Criança; Adolescente; Exploração sexual; Populações vulneráveis; Direitos humanos; Saúde mental. 


\section{Abstract}

This paper reports experiences of the project "Recreated Routes: Children and adolescents free from sexual exploitation", which brings up, from a socialcultural perspective, ways to face sexual exploitation of children and teenagers in Campinas - SP. With different axis of action, with aspects of inter sector and interdisciplinary approach, the project has as theoretical base the development of some primary actions, with the objective of promoting debate in order to build a public policy for facing this relevant subject. It presents the experience of health intervention, through work with one of the target populations in the project: children and teenagers living on the streets and being sexually exploited. It is based on the needed articulation between health and human rights, since negligence and violation of rights could result in health consequences, in a social-cultural context. It aims to guarantee and respect the rights of this excluded population. It is based in therapeutical follow up as a strategy to attach individual and collective needs, including interventions based on rights promotion and assurance. Reports based on history of life "scenes" were used, targeting the decrease of social vulnerabilities and the full exercise of rights of this population.

Keywords: Children; Adolescent; Sexual Exploitation; Vulnerable Populations; Human Rights; Mental Health.

\section{Exploração Sexual, Direitos Humanos e Saúde}

Este artigo se dedica ao debate sobre intervenções em políticas públicas direcionadas à questão de crianças e adolescentes envolvidos com o mercado do sexo, no contexto urbano de grandes cidades, em situação de miserabilidade e vivendo nas ruas. Esse cenário engendra uma série de violações aos direitos humanos, o que gera profundas conseqüências e desdobramentos prejudiciais aos sujeitos, incluindo a dimensão da saúde.

Esses sujeitos são privados das condições básicas para uma vida digna (Bobbio, 2004) - o que é o fundamento da Declaração Universal dos Direitos do Homem.

Na medida em que se compreende a saúde composta de componentes de bem-estar físico, mental e social, parece pertinente concluir que a violação de qualquer direito humano terá impacto desfavorável à saúde (Gruskin e Tarantola, 2002).

O relato a seguir, oriundo do campo da saúde mental, mostra, com indignação, a constatação de que a realidade do fenômeno da prostituição, compreendida sob o conceito de exploração sexual comercial infanto-juvenil, atrelada a uma série de outros fatores de vulnerabilidade, tem alto impacto sobre a construção da subjetividade desses sujeitos, com comprometimento dos processos de construção de identidades, do desenvolvimento psicossocial e da formação do sujeito sexual ${ }^{1}$.

A exploração sexual pode ser definida como: “(..) uma relação de mercantilização (exploração/dominação) e abuso (poder) do corpo de crianças e adolescentes (oferta) por exploradores sexuais (mercadores), organizados em redes de comercialização local e global (mercado), ou por pais, ou responsáveis, e por consumidores de serviços sexuais pagos (demanda)" (Leal, 20o3, p.8).

A exploração sexual comercial de crianças e adolescentes - ESCCA - desdobra-se nas modalidades atualmente constatadas no mundo da economia global: prostituição, turismo sexual, pornografia e tráfico para fins sexuais (Leal, 2003).

\footnotetext{
1 A dimensão do sujeito sexual específica, dentre outras da vida humana, é definida por Paiva (1999) como aquela que regula cada experiência sexual, estando sob influência das normas culturais que definem os gêneros masculino e feminino. A noção de sujeito, segundo a autora, integra a idéia de agente de construção da cidadania, na tradição da educação libertadora de Paulo Freire.
} 
Trata-se de um fenômeno multidimensional de extrema violação de direitos do ser humano, dentre eles, o direito ao exercício de uma sexualidade saudável. 0 tema, além de prioritário, passa a figurar entre os mais desafiadores e contundentes da agenda social do país, exigindo do Poder Público e da sociedade um esforço conjunto de enfrentamento e de coibição de sua prática.

A experiência sobre a qual debruçamos nossas reflexões insere-se no enfrentamento da prostituição infanto-juvenil em território urbano, sendo que adotamos o conceito de crianças e adolescentes prostituídos e em situação de exploração sexual, apesar do conceito de exploração envolver outros âmbitos de atuação. Trata-se de um posicionamento, pois consideramos que a criança e o adolescente estão em situação peculiar de desenvolvimento, conforme definido pelo Estatuto da Criança e do Adolescente - ECA (Brasil, 1990) -, sendo necessária a proteção de seus direitos (Faleiros, 2000).

Para o estabelecimento de ações nesse campo fazse necessário considerar as multi-causalidades que envolvem a problemática da violência sexual infantojuvenil $^{2}$, a essencial implantação de programas intersetoriais e a construção de redes de serviços com fluxos complementares (Vasconcelos e Malak, 2002).

Neste cenário as ações de saúde pública podem ter efeito positivo sobre os direitos humanos (promoção e correção de violações), lembrando que a atenção à saúde, quando acessível e de boa qualidade, pode garantir a realização do direito à saúde e à vida, conforme expresso no ECA (França Júnior e Ayres, 2003).

A proposta que tentamos desenvolver na prática cotidiana da intervenção com esta população, na qual o desafio passa pela construção de metodologias, fundamenta-se no enfoque das necessidades individuais, pautadas na perspectiva do direito, buscando a mediação baseada em seu interesse superior, segundo o princípio estabelecido pela Convenção (ONU, 1989).

A partir da prática com os sujeitos que acompanhamos, meninas e meninos em situação de rua e de exploração sexual, observamos que muitos direitos estabelecidos por Convenções e Leis nacionais e internacionais são violados.

A situação de rua em si demonstra a violação de direitos básicos garantidos e priorizados para as crianças e adolescentes, pois estar na rua, em muitos casos, é conseqüência ou agravamento de violação de direitos.

No âmbito nacional, segundo preconiza o Estatuto da Criança e do Adolescente (Brasil, 1990), com relação à referida população, são violados direitos: à vida e à saúde (capítulo I); à liberdade, ao respeito e à dignidade (capítulo II); à convivência familiar e comunitária (capítulo III); à educação, à cultura, ao esporte e ao lazer (capítulo IV).

Viver nas ruas representa o estado do não-exercício de certos direitos, como, o direito: à convivência familiar (art. 19); à educação (art. 53), pois grande parte dessa população é considerada "evadida" pelo sistema formal de ensino; de ser considerado em sua privacidade, autonomia e identidade (art. 17); de não estar em situação vulnerável para diversas formas de exploração, dentre elas a sexual (art. 18); de ter um desenvolvimento saudável (art. 7), uma vez que a vulnerabilidade a os agravos físicos, por exemplo, a DSTs/Aids, e psíquicos, encontram-se presentes.

Por fim, com base no escopo apresentado, dedicamo-nos a embasar uma metodologia de ação em saúde com a perspectiva de inserção da dimensão dos direitos humanos.

\section{Uma Leitura da Experiência: o Projeto Rotas Recriadas}

A experiência que relataremos se desenvolveu dentro do Projeto Rotas Recriadas: Crianças e Adolescentes livres da Exploração Sexual, em Campinas-SP³, implementado pela Prefeitura Municipal de Campinas, em uma proposta intersetorial e reunindo ainda ONGs (Organizações Não-Governamentais) locais e o Conselho Municipal de Direitos da Criança e do Adolescente - CMDCA/ Campinas. Esse projeto contou com o financiamento da Petrobras, através dos recursos de isenção fiscal (Projeto Rotas Recriadas, 2004).

\footnotetext{
2 Utilizamos aqui o conceito de violência sexual segundo Faleiros (200o), como categoria ampla que inclui abuso sexual extra e intrafamiliar e a exploração sexual comercial.

3 Projeto premiado no $4^{\circ}$. Marketing Best de Responsabilidade Social, tendo sido apresentado pela empresa Petrobras, através de seu financiamento para implementação das ações.
} 
Em Campinas encontramos os problemas dos grandes centros urbanos, como altos índices de criminalidade e violência, desemprego, pobreza e intenso fluxo migratório das regiões mais pobres do país, cujas contingências se expressam na dificuldade psicossocial de as famílias prover o sustento, o cuidado e a proteção de suas crianças e jovens. O cenário reflete o impacto de fenômenos macroeconômicos na violação dos Direitos da Criança (Leal, 2003).

No âmbito das Políticas Públicas, a institucionalização do programa Rotas Recriadas no Município inseriu-se no Plano Municipal da Infância e Juventude e no Plano Municipal de Enfrentamento à Violência Sexual Infanto-Juvenil (Câmara Municipal de Campinas, 2003). Almejava-se que as estratégias traçadas propiciassem, com resolutividade, ações na direção da prevenção, do enfrentamento e do cuidado.

Especificamente na esfera da promoção da atenção às crianças e adolescentes em situação de exploração sexual, foi criado o eixo cuidar ${ }^{4}$ concebido com o intuito de ofertar para a população-alvo cuidados em saúde, em especial e à saúde mental, para apoio, formação de vínculo e auxílio para a construção conjunta e participativa de novos projetos de vida, que se traduzissem na (re)criação de novas rotas de vida.

Considerando a complexidade do fenômeno da exploração sexual de crianças e adolescentes, justificava-se a implantação do eixo cuidar pela necessidade de ampliar ações, qualificar o cuidado, através da interdisciplinaridade, além de suprir as lacunas no atendimento, contribuindo para a diminuição da demanda reprimida já existente nos equipamentos sociais da cidade.

Como estratégia de implementação da intervenção, o eixo cuidar operacionalizava-se através de três frentes: inserção de um técnico de saúde mental em cada Distrito de Saúde da cidade ${ }^{5}$, criação de uma equipe especial para a região central, local notoriamente reconhecido como espaço de maior concentração da temática no Município, e alocação de um técnico para atuação na região de um bairro historicamente conhecido como região de prostituição local.

Cada Distrito conta com uma rede de equipamentos de saúde e serviços sociais. As ações em saúde são pensadas no âmbito do apoio matricial (Campos, 200o) aos trabalhadores da região. Entende-se por apoio matricial a oferta de conhecimentos, propostas, ações e intervenções conjuntas. O Projeto Rotas Recriadas, através do eixo cuidar, inseriu um técnico "cuidador" em cada Distrito, com o intuito de pautar o tema da violência sexual, levantar demanda reprimida, acolher nova demanda e encaminhar um fluxo de ações. 0 local de referência para estes profissionais eram os Centros de Saúde, com o intuito de promover o acolhimento em um local próximo à residência do usuário, facilitando o seu acesso.

A equipe do centro estava alocada em um CAPS Centro de Atenção Psicossocial - dedicado ao atendimento de meninos e meninas em situação de rua e/ou usuários de substâncias psicoativas. A escolha deste equipamento ocorreu em função de a equipe já existente concentrar uma grande quantidade de atendimentos de casos que apresentavam uma interface com a exploração sexual, embora esse fator nunca tivesse sido abordado em sua particularidade. Sobre este ponto dedicamos as análises subseqüentes.

Os territórios da cidade em que nos inserimos expressavam diferenças consideráveis relacionadas aos perfis daquela população. Fato que nos levou a traçar estratégias específicas que interagissem com as particularidades de cada local, buscando, a partir do conhecimento e da cultura estabelecidos, criar formas de aproximação da população-alvo.

A equipe do eixo cuidar alocada na região central dirigiu suas ações a meninas e meninos em situação de rua ${ }^{6}$ ou aqueles que transitavam pelas ruas centrais na prática do trabalho infantil. Tanto em relação às crianças e aos adolescentes que residiam nas ruas,

\footnotetext{
4 O Projeto Rotas Recriadas foi metodologicamente concebido por eixos de atuação: eixos capacitar, buscar e diagnosticar, prevenir, cuidar, fiscalizar, comunicar e gestar (Projeto Rotas Recriadas, 2004).

5 A divisão distrital segue os princípios do Sistema Único de Saúde - SUS -, que preconiza a descentralização do atendimento à saúde, de modo que o território de Campinas encontra-se subdividido em regiões/distritos com Serviços de Saúde circunscritos a cada um.

6 "Por menino de rua, definiu-se aquele que foi visto quando estava trabalhando em biscates, esmolando, perambulando ou exercendo atividades ilícitas. Além de ser feito à distância, dependendo do olhar do educador, treinado ou não, tal procedimento é duvidoso pela forma como define a quem contar: ele abrange crianças que trabalham nas ruas, mantêm vínculos familiares e freqüentam escolas, crianças que moram nas ruas com as famílias e crianças cujos vínculos familiares estão mais esgarçados” (Gregori, 20oo, p. 20).
} 
como àqueles que passavam o dia vendendo flores e balas e retornavam as suas casas apenas para dormir, constatou-se, em alguns casos, principalmente nas meninas, o envolvimento com a prostituição/ exploração sexual comercial. Sobre ambas as populações é que se dirigem, prioritariamente, as análises, problematizações e a tentativa de desenvolver tecnologias sociais, no campo da saúde, embutidas na perspectiva dos direitos humanos.

Uma parcela da população que estava naquele momento em situação de rua encontrava-se em vulnerabilidade para a situação de exploração sexual, parecendo ser este mais um fator que acometia suas vidas, dentro de um quadro mais amplo de vulnerabilidades sociais: vínculos rompidos ou esgarçados com a família, migração das regiões periféricas (carentes de equipamentos sociais) para as ruas da região central da cidade, evasões escolares, práticas de atos infracionais, uso abusivo de substâncias psicoativas (com preponderância do crack), dentre outros. Observou-se um progressivo processo de exclusão e ausência dos direitos básicos, de modo que se envolver com a prática da prostituição nas ruas centrais parecia ser um meio de aquisição de recursos financeiros, ou outros bens, como: droga, um espaço para pernoite, alimentação; pode caracterizar também uma forma de atuação como sujeito social, ocupando o cenário disponível.

Vale destacar que essa descrição acerca do quadro das vulnerabilidades e da violação de direitos é aplicável a ambos os gêneros, embora o decorrer da intervenção tenha indicado que as motivações psicossociais e culturais dentre meninos e meninas, as práticas e performances no campo da prostituição, bem como a relação que se estabelecia entre menina e "cliente" e menino e "cliente" guardavam significativas diferenças.

Sobre a prostituição de meninos, o que pudemos constatar está de acordo com o que é descrito pela literatura sobre prostituição masculina. Caracteriza-se pela falta de visibilidade social, o anseio dos indivíduos pelo anonimato, a prática mais freqüente e concentrada em espaços privados, bem como pela conotação de uma prostituição do tipo homossexual (Fábregas-Martínez, 2002).
No contexto do trânsito pelas ruas e por territórios de comercialização do sexo, havia as e os adolescentes que se "auto-agenciavam”, por não mais “despertarem" o interesse de terceiros, pois freqüentemente estavam em situação de uso abusivo de substâncias psicoativas, com conseqüências nos cuidados pessoais, na saúde e na integridade física e psíquica, de modo que os "programas sexuais" tinham a finalidade de prover o próprio vício. Vale lembrar que também havia meninas e meninos que eram aliciados para que integrassem estabelecimentos e fluxos de comércio do sexo, que compunham a rede mais organizada de exploração.

O tripé que caracterizava a população aqui descrita se dava entre: estar em situação de rua (residindo ou no trabalho informal), usar, de modo abusivo, substâncias psicoativas e estar em situação de exploração sexual comercial, nos moldes do que, historicamente, chamamos de prostituição.

Propondo-nos a trabalhar com jovens de ambos os sexos, e com a diversidade em termos de identidades de gênero e sexual, observávamos que as cenas e os cenários sexuais ${ }^{7}$ envolvendo a prostituição eram tão diversos quanto à diversidade das identidades. Havia os jovens travestis para os quais a prática da prostituição estava ligada à possibilidade de expressão da feminilidade, no sentido subjetivo singular; os adolescentes que se identificavam segundo uma identidade de gênero masculina, fazendo sexo com homens somente como uma "atividade para ganhar dinheiro" e discordantes de uma identidade gay; e ainda, aqueles adolescentes que estavam construindo, por meio das experiências no mercado do sexo, uma trajetória de experimentação (ou de aceitação) da homossexualidade, bastante inseguros quanto aos próprios desejos e vulneráveis ao estigma e à discriminação, principalmente da rede familiar.

Situada no campo da sexualidade e em uma abordagem construcionista, a vulnerabilidade à prostituição/exploração sexual da população descrita não pode prescindir a noção de que as normas culturais que definem os gêneros masculino e feminino afetam, significativamente, o que se faz sexualmente (Paiva, 1999). 
Deste modo, o desafio do Projeto Rotas Recriadas foi a criação de metodologias que, considerando os fatores sociais, culturais e históricos que regulam as práticas sexuais entre os indivíduos, possibilitassem o acesso às crianças e aos adolescentes em situação de exploração sexual, ofertando-lhes a possibilidade de construção de novos projetos de vida.

\section{O Acompanhamento Terapêutico: saúde mental e promoção dos direitos humanos}

O referencial que nos orientou acerca das ações no trabalho com a população de crianças e jovens em situação de rua e exploração sexual subsidiou-se pelas contribuições, reflexões e práticas da saúde pública, da saúde mental e dos direitos humanos.

Com um olhar ampliado para o contexto sociocultural, buscávamos dimensionar as vulnerabilidades sociais a que estavam expostos as crianças e os adolescentes: os direitos violados ou negligenciados, os agravos da saúde e os impactos na qualidade de vida e iniciávamos a construção de um projeto de trabalho junto a eles ${ }^{8}$.

Esse projeto incluía uma dimensão terapêutica que levasse em conta o âmbito das subjetividades, ou seja, o auxílio ao desenvolvimento dos sujeitos e a criação de perspectivas pautadas na possibilidade de sonhar o futuro, bem como de "amenizar as dores (...), físicas e psíquicas, que os abandonos sucessivos e a vida nas ruas lhes impuseram" (Lesher, 2002, p.3).

O diferencial que almejávamos, com a proposta terapêutica de abordagem da subjetividade singular, era incluir a dimensão dos direitos humanos incluindo a saúde mental, o que requereria uma mudança do ponto de vista técnico e metodológico do trabalho.

Buscando alcançar o âmbito coletivo de inserção desta população e tendo em vista outras experiências de intervenção frente à exploração sexual (Franca, Teixeira e Goratti, 2002), elegemos o Acompanhamento Terapêutico como método de trabalho.
O uso dessa nomenclatura ancora-se no campo da saúde, porém não pretende advogar a maior relevância deste campo sobre os demais, pois a exploração sexual é um problema complexo de necessária abordagem intersetorial. Optou-se pelo uso da terminologia "acompanhamento terapêutico" por ela se fundamentar em experiências práticas no campo da saúde mental e na luta pelos direitos humanos daqueles que se encontram, ou se encontravam, em situação de sofrimento psíquico.

O acompanhamento terapêutico tem raízes históricas no Movimento Anti-psiquiátrico, na Luta Antimanicomial e na Psicologia Institucional, no início da década de 1950, tendo como uma grande referência o fechamento do Manicômio de Trieste, na Itália, e o processo de "desinstitucionalização" subseqüente ${ }^{9}$ (Basaglia, 1985).

O Movimento Antipsiquiátrico promoveu críticas aos tratamentos em saúde mental, formulando novas concepções de cuidado a partir da desospitalização, da (re)inclusão social, considerando o isolamento como um fator de agravo do sofrimento psíquico (Carvalho, 2004).

Esse movimento questionou a condição do "doente mental" como sujeito destituído de direitos, trazendo para a saúde mental a esfera dos direitos humanos. Denunciou a violação do direito à liberdade, à livre expressão e à convivência social (Bertolote, 1995). Essa discussão se mantém até os dias atuais para o embasamento de intervenções direcionadas às pessoas em situação de sofrimento psíquico.

Traçando um paralelo entre este período histórico e a atualidade, contextualizando as novas configurações da sociedade contemporânea, apropriamo-nos deste legado para refletir sobre as demandas em saúde mental no âmbito público, em especial na esfera da infância e juventude.

Se o contexto da luta antimanicomial referenciouse nos direitos humanos em favor daqueles em sofrimento psíquico, utilizamo-nos das mesmas bases para o debate da situação da infância e da juventude em vulnerabilidade social e violência.

\footnotetext{
8 Utilizaremos o gênero feminino para referência às adolescentes por terem sido o universo prevalente no grupo de trabalho.

9 Com o processo de desinstitucionalização houve a demanda e a conseqüente criação de serviços substitutivos, como Hospital Dia, Oficinas, Centros de Convivência, Residências Terapêuticas, e, como local de referência de nossa experiência, os Centros de Atenção Psicossocial - CAPS. Estes equipamentos têm a finalidade de proporcionar um tratamento humanizado e a inclusão da dimensão de direitos e cidadania.
} 
Apoiando-nos nesses princípios históricos, elegemos o "acompanhamento terapêutico" - AT - por pontuar as diretrizes de intervenção (Equipe de ATs de "A casa", 1991):

- Operatividade/Funcionalidade para intervenções em situações de vulnerabilidade social que favoreça a vulnerabilidade psíquica.

- Metodologia possível em situações de extrema vulnerabilidade social diante da insuficiência de terapias individuais, grupais, familiares e medicamentosas, sem negar sua relevância.

- Dimensão terapêutica implicada em ação nos diversos espaços sociais, no cotidiano, para uma escuta clínica sustentada por uma relação transferencial.

- Estabelecimento de um "contrato" com o sujeito envolvido;

- Ação baseada em um "fazer" pautado pelo que o sujeito deseja (ex: cursos de beleza, comprar cigarro), necessita (ex: tirar documentos, consultas médicas), ou ainda pela promoção de experiências e vivências diferenciadas de seu contexto social (ex: ir ao cinema, teatro, oficinas).

- Posição de não confinamento (clausura subjetiva: dependência química, vivências nas ruas etc.; e clausura concreta: hospital psiquiátrico, FEBEM etc.), de modo que o sujeito e suas relações sejam cuidados além dos muros institucionais.

O AT pode ser caracterizado por um conjunto de ações de socialização e cuidado que ocorre no cotidiano da pessoa, na sua casa, na rua, no ônibus, em espaços sociais etc. Dessa maneira, o processo terapêutico difere-se do tradicional, pois a intervenção busca, a partir de situações reais da vida coletiva, contemplar as necessidades e os desejos da pessoa.

A utilização desta metodologia só faz sentido quando inserida em uma rede de atendimento intersetorial que partilhe, entre os serviços e os profissionais envolvidos, o projeto em andamento e a responsabilização por ele, não desconsiderando a autonomia e a capacidade de escolha do sujeito em questão.

\section{Vulnerabilidade: dispositivo de análise e ação}

O conceito de vulnerabilidade, central dentro da perspectiva teórica construcionista adotada diante da rea- lidade empírica, é aqui utilizado desdobrando-se em duas dimensões: vulnerabilidade social e vulnerabilidade psíquica.

Originário da área da advocacia internacional o conceito designa, em sua origem, grupos ou indivíduos fragilizados, jurídica ou politicamente, na proteção ou na garantia de seus direitos de cidadania (Alves, 1994). Passou a fazer parte do campo da saúde há aproximadamente dez anos, como um conceito-chave nos estudos e intervenções diante da epidemia de HIV/ AIDS.

"a proposta da vulnerabilidade aplicável, rigorosamente, a qualquer dano ou condição de interesse para a saúde pública, pode ser resumido justamente como este movimento de considerar a chance de exposição das pessoas ao adoecimento como a resultante de um conjunto de aspectos não apenas individuais, mas também coletivos, contextuais, que acarretam maior suscetibilidade aos adoecimentos" (Ayres e col., 2003, p. 123).

Contrastando com o conceito de risco, a vulnerabilidade tem a premissa de buscar identificar a coparticipação, a síntese das variáveis que estejam envolvidas na suscetibilidade ao adoecimento, sejam elas abstratas, subjetivas ou estruturais, ao contrário do isolamento das varáveis e da busca de uma relação causal bilateral, consonante ao conceito trabalhado por Ayres.

Nota-se, a partir dos referenciais citados, um caráter descritivo e analítico para a utilização da vulnerabilidade como dispositivo conceitual, de modo que a simples troca entre os termos "risco" e "vulnerabilidade", aspecto comumente observado, descontextualiza os propósitos de ambos os conceitos, menosprezando as funcionalidades da categoria "risco" para os estudos epidemiológicos.

A idéia da vulnerabilidade social tem sido eficaz para chamar a atenção sobre as condições estruturais que colocam as pessoas em risco, para além do seu comportamento individual, mais ou menos "irresponsável” (Pitanguy, 2003). Classe, etnia, gênero e nacionalidade são sistemas de classificação social oriundos de estruturas de desigualdade que também distribuem os riscos em saúde de maneira desigual.

Ayres e col. (2003) apresentam alguns componentes importantes para avaliar condições de maior ou menor vulnerabilidade social de um indivíduo ou de 
vários. São eles: acesso aos meios de comunicação, escolarização, disponibilidade de recursos materiais, poder de influenciar decisões políticas, possibilidade de enfrentar barreiras culturais, estar livre de coerções violentas ou poder defender-se delas.

Diante da complexidade da situação que abordamos, discorremos sobre a nossa proposição do conceito de "vulnerabilidade psíquica" como uma dimensão da vulnerabilidade, que possivelmente possa dialogar com o componente individual da vulnerabilidade proposto por $A_{y r e s^{10}}$. Propomos aprofundar a reflexão acerca da dimensão da subjetividade singular e da subjetividade compartilhada por um grupo específico, assim como nos situarmos em um debate sobre a operacionalização do conceito de vulnerabilidade no campo da saúde mental em interface com a saúde pública.

O conceito de vulnerabilidade psíquica, que propomos, nos parece pertinente pela possibilidade de pensarmos fatores potenciais de modo que, sinergicamente, componham condições propulsoras ao sofrimento ou ao adoecimento psíquico. Esses fatores estariam relacionados tanto ao universo cultural, histórico e social, daí a dimensão da vulnerabilidade social, como às experiências de vida singulares que, combinados, seriam a matéria-prima para a constituição das subjetividades. Sofrimentos psíquicos presentes em larga escala na população de crianças e adolescentes que vivenciam experiências de rua (com todo o impacto das violências múltiplas, incluindo a exploração sexual como uma delas) exteriorizam-se na forma de depressão, transtornos de condutas, agressividade generalizada, hiperatividade, uso abusivo de substâncias psicoativas, dentre outros.

Assim, pauta-se a violação de seus direitos como elemento central para a discussão de todos estes desdobramentos e conseqüências para a saúde. Uma vez que os direitos básicos não foram respeitados, e frisa-se aqui a necessidade de desenvolver intervenções que se dediquem a este aspecto, passamos a buscar a promoção do direito ao cuidado, de expressão, de ressignificação das rotas de vida.

Como conseqüência de todas essas violações, pauta-se a questão: como fazer a leitura das estruturas intrapsíquicas e das sintomatologias (uma vez que não são dadas naturalmente), levando-se em conta o contexto sociocultural, com as respectivas transversalidades de gênero, classe social, geração e etnia?

Os termos aqui utilizados como "vulnerabilidade psíquica", "acompanhamento terapêutico", dentre outros, partem de nosso lugar de origem - a saúde -, mas podem ser debatidos, redefinidos ou renomeados, de acordo com o processo.

Fazendo a transposição do conceito de vulnerabilidade para o campo da saúde mental, a articulação entre as noções de vulnerabilidade social e vulnerabilidade psíquica tem duas conseqüências positivas: a primeira é a negação de uma tradição "psicologizante", essencialista, individualista, culpabilizadora e a-histórica, que renega qualquer reflexão sobre os contextos culturais, sociais e políticos "onde" e "como" as pessoas sofrem e adoecem. Essas considerações possibilitam a segunda conseqüência que seria o estabelecimento de formas de "tratamento" que ultrapassem e transcendam o que historicamente é entendido como "da saúde", de modo que as mudanças ou propostas das políticas sociais requeiram a intersetorialidade e a interdisciplinaridade. Referimo-nos, objetivamente, a ações com impacto estrutural, no campo da educação, do esporte e da cultura, do trabalho e da geração de renda, dos direitos, entre outros, voltadas, segundo nossa experiência, à juventude.

A discussão da vulnerabilidade a que nos dedicamos, tem como enfoque crianças e jovens em situação de rua, de miserabilidade e exploração sexual, partindo do olhar da saúde mental no contexto da saúde coletiva. Para a análise de intervenções com essa população em complexa situação social, pautamo-nos na questão: que experiências vivem as jovens, em um contexto de vulnerabilidade social, portanto de não garantia de direitos à proteção integral, que favorecem as condições de sofrimento e, em alguns casos, de adoecimento psíquico?

O objetivo é apresentar o relato de uma experiência de intervenção psicossocial com jovens em situação de exploração sexual, com as quais se utilizou a metodologia do acompanhamento terapêutico, como instrumental de acolhimento na perspectiva de promoção de direitos. Problematiza-se o uso do acompanhamento terapêutico como técnica que possibilita a abordagem da população infanto-juvenil, com o intui-

1o Sobre os componentes individual, social e programático da vulnerabilidade ver Ayres (2003). 
to de construir uma proposta que seja simultaneamente terapêutica e de ação social.

\section{O Cenário da Intervenção}

A experiência que relatamos foi desenvolvida em Campinas - na fase de implementação do projeto Rotas Recriadas - durante um período de nove meses, da qual fizemos parte como atores do processo, como técnicas em intervenção na região central.

Após esse período, o projeto foi redesenhado pelos gestores locais, passando por modificações em seu desenho e em suas estratégias, em função da diminuição da disponibilidade de recursos para sua manutenção e da mudança de diretrizes governamentais para a institucionalização da proposta desenvolvida.

Durante o período inicial, sobre o qual debruçamos nossas análises, o eixo cuidar do projeto atendeu, através dos equipamentos de saúde, 75 crianças e adolescentes do município; desse total, 18 encontravam-se sob a responsabilidade da equipe do centro, por estarem em situação de rua e de exploração sexual.

Relatamos aqui uma apresentação sucinta dos dados referentes aos adolescentes em acompanhamento na região central da cidade, foco deste trabalho. Os dados e o detalhamento das intervenções realizadas nos distritos não serão abordados por extrapolarem a análise proposta.

Em dados gerais, observamos uma prevalência de adolescentes oriundos de regiões periféricas da cidade, especialmente de ocupações e/ou favelas, reforçando o dado recorrente de que a pobreza é um fator relevante, mas não único, para se incluir na abordagem de exploração sexual (Leal, 2003). Esse aspecto reforça a necessidade de programas de distribuição de renda para esta população. A precariedade de equipamentos sociais apresenta-se como outra característica comum desses bairros, levando ao apontamento de outro indicador influente no que circunda esse fenômeno.

Durante o período de trabalho, tivemos uma maior freqüência de meninas, totalizando 16 dos 18 atendimentos relatados. Contudo, havia também a presença de meninos envolvidos com a prostituição dita homossexual, identificados como "michês" ou travestis, distribuídos em territórios distintos da cidade. 0 acesso a esses grupos era mais difícil, pois os travestis eram aliciados por "cafetinas" e estavam "enfeitiçados" pela possibilidade de realizar o sonho da feminização do corpo com as próteses cirúrgicas de silicone. Para isso, faziam dívidas pagas com o trabalho no mercado do sexo, segundo uma lógica exploradora de semi-escravidão. Essas características tornavam-nos mais "escondidos", devido à ilegalidade que os acompanhava, sendo difícil encontrá-los em espaços públicos e em equipamentos sociais por onde atuávamos.

No caso dos meninos ditos "michês" a reclusão em espaços como saunas e boates, bem como a concentração dos encontros em pontos específicos, como banheiros masculinos de um parque da cidade, tornava o acesso a eles bastante difícil. Tínhamos a sensação de ser esse um universo no qual não nos era permitido entrar, fator relacionado, dentre outros, ao fato da própria identidade feminina, como profissionais em intervenção.

Quanto à faixa etária, houve uma incidência maior de adolescentes e jovens com idade entre 15 e 18 anos. Vale destacar, contudo, que contávamos também, com a presença de adolescentes mais jovens, tendo um grupo de seis meninas com idade entre 13 e 14 anos. Havia, ainda, a presença de duas crianças, que iniciaram suas vivências nas ruas entre os seis e sete anos de idade, e, com o tempo, passaram a realizar programas sexuais por trocas diversas em seu cotidiano.

A breve apresentação acima objetivou explicitar um panorama da intervenção, que nos permitirá, a partir daqui, enfocar cenas individuais do acompanhamento terapêutico realizado, tecendo alguns comentários sobre a experiência em questão.

\section{o Cenário Microssocial da Intervenção: trajetórias singulares}

Para que se tenha uma visualização da intervenção ancorada na realidade empírica, considerando o projeto de trabalho com cada adolescente singular, é necessário que apresentemos a implementação do AT em seu esforço por produzir sentidos e significados nas vidas com as quais lidávamos, de modo a evitar massificações.

Para isso, ilustramos o debate mencionado por meio de algumas das "cenas" ${ }^{11}$ que se produziram nos

11 As cenas estão relatadas no tempo presente para que se possa preservar a noção de temporalidade no desenvolvimento da intervenção. 
cotidianos transcorridos da experiência em questão. Pela maior prevalência das adolescentes, assumimos desde já uma limitação desta apresentação, que se coloca pelo fato de compartilharmos a realização do AT com duas meninas, o que se justifica pela dificuldade de acesso aos meninos, o que não propiciou efetivamente um projeto mais consistente com eles. Algumas intervenções foram realizadas na tentativa de buscá-los e acolhê-los - com dois deles isso aconteceu, foram promovidas ações de cuidados em saúde, inserção em atividades socioeducativas e iniciação de vínculo -, contudo pela brevidade do tempo da etapa-piloto, não foi possível o desenvolvimento de um projeto propriamente de AT.

Vale ressaltar que apresentaremos nomes fictícios nos relatos abaixo, condizentes com os aspectos éticos. Estabelecíamos, durante o processo terapêutico, um contrato com a adolescente, garantindo-lhe confidencialidade dos momentos vivenciados durante nossa abordagem.

Amanda tem 14 anos e vive em uma favela, oriunda de uma ocupação na cidade, e nas ruas da região central; encontra-se neste trânsito há cerca de quatro anos. Sua família é migrante da região nordestina do país, já tendo passado por diferentes cidades até chegar a Campinas, onde vivem em situação de extrema pobreza socioeconômica e cultural. Sabe-se, através do relato de Amanda, que a irmã mais velha e a mãe vieram "fugidas", pois queriam sair da condição de violência familiar personalizada na figura do pai biológico dos quatro filhos e primeiro marido de sua mãe, descrito como figura extremamente violenta, que as submetiam a rituais de crueldade como "acordar todo mundo no meio da noite pra apanhar” (sic). A nova composição familiar é composta de um padrasto "distante", pai da filha caçula de dois anos, que não parece ocupar um lugar de autoridade paterna, sendo descrito por Amanda como aquele que "não gosta dos filhos da minha mãe que não são dele”. A mãe expressa conflito entre a maternidade associada ao primeiro projeto conjugal e a (re)configuração da família, pois se preocupa muito em não perder "outro casamento" e ainda deixar "mais uma filha igual às outras, sem um pai ${ }^{\prime 2}$.

Iniciamos nossa aproximação, quando a adoles- cente fazia uso abusivo de substâncias psicoativas, tinha envolvimento diário com a prostituição, evadiu da escola, há cerca de três anos, com retornos para a casa cada vez mais escassos, estruturando, progressivamente a rua como seu espaço de vida.

Conhecemos Amanda em um momento em que ela se expressava com muita tristeza e mágoa, parecendo-nos ser freqüente estar em situações de alta vulnerabilidade para sua integridade física e psíquica, como: internações noturnas nos prontos-socorros, por ter sido encontrada em logradouros públicos “desacordada"; sofrimento de violência física, através de tentativa de estrangulamento por suposto "cliente", dentre outras.

No transcorrer de seu projeto sócio-terapêutico, a partir de uma avaliação dos serviços com relação aos agravos decorrentes do uso abusivo de substâncias psicoativas e das situações acima mencionadas, trabalhou-se para auxiliá-la a reconhecer a necessidade, naquele momento, de cuidados intensivos.

Encontrá-la nas ruas e perambular conjuntamente foram as estratégias de acompanhamento escolhidas para a realização de diálogos que pudessem apresentar-lhe novas opções de escolha. A partir daí decorreu o encaminhamento para uma internação em um serviço de desintoxicação para uso de drogas.

Saindo da rua, o serviço de internação passa a ser o lócus de continuidade da intervenção em andamento, espaço de presença constante da técnica de referência que se dedica ao acompanhamento terapêutico da adolescente.

Para a promoção da internação pautamo-nos pelo direito à vida e à saúde, segundo o ECA, visando agir para a proteção de sua integridade, além da redução do quadro de vulnerabilidades ao qual estava exposta, principalmente devido às múltiplas violências sofridas, que feriam seu direito à dignidade e ao respeito.

No processo de internação houve uma reaproximação da família, através da promoção de encontros entre mãe e filha, articulando a proposta do projeto terapêutico da adolescente.

Na discussão da alta, Amanda passa a demonstrar como necessidade emocional o retorno a sua casa e, em especial, junto à mãe, apesar do esgarçamento do vínculo com esta casa. Sua família apresenta um his-

12 Aspectos de acordo com a literatura sobre as famílias pobres e a construção da moralidade, segundo Sarti (2003). 
tórico de negligência com a maior parte dos filhos, segundo informações do Conselho Tutelar local, más condições econômicas para a provisão de necessidades básicas, tal como alimentação, acrescido ao fato de que a mãe demonstra dificuldade de continência afetiva com esta filha.

O dilema encontrado relacionava-se em atender a necessidade apresentada pela adolescente, do retorno para a casa e convivência com a mãe, e, ao mesmo tempo, promover alguns de seus direitos básicos, como alimentação, espaço de proteção e cuidados em saúde. A opção apresentada para garantir estes direitos dava-se através da realização de seu abrigamento em uma instituição, local com o qual já tinha familiaridade, por ser um equipamento para adolescentes em situação de rua.

Para além das questões concretas do âmbito econômico, para as quais se buscaram recursos assistenciais, questionava-se a possibilidade de continência e acolhimento para a adolescente, há alguns anos a margem da convivência familiar, sendo que o fracasso dessas ações poderia contribuir para o retorno dela às ruas e às vulnerabilidades deste contexto.

Apesar das mencionadas fragilidades do contexto, optou-se pelo retorno à família, desejo expresso tanto por Amanda como por sua mãe, respeitando o direito à convivência familiar e comunitária, intervindo em favor da ressignificação dos vínculos familiares, em especial o vínculo com a mãe. Para isso, disponibilizamos suportes psicossociais, para que a rede social e pessoal significativa passasse a ser assumida como espaço prioritário de trabalho, na continuidade do percurso do acompanhamento terapêutico.

Vislumbrava-se que esse seria o momento propício para a realização do trabalho com o contexto familiar, investindo no fortalecimento dos laços entre mãe e filha, que era o desejo de Amanda.

A "cena" acima ilustra a tentativa que empenhamos na relevante junção entre atender às necessidades e promover os direitos, pois esses aspectos não se segmentam na vida prática cotidiana. Utilizou-se como princípio da opção adotada priorizar o interesse superior da criança (ONU, 1989), ou seja, ações que conduzissem a garantia de alguns de seus direitos mais significativos naquele momento. Compreendeu- se, portanto, que a dimensão afetiva e relacional emergiu como superior diante das carências econômicas concretas, sobre as quais se trabalhava com a hipótese de abrigamento.

Amanda, portanto, retornou para a casa e seu acompanhamento transcorreu nesse espaço.

Outra intervenção que nos suscitou a discussão da promoção dos direitos referiu-se à obtenção de documento de identificação para essa população, que sequer exercia um dos direitos básicos da cidadania, ter uma documentação que a legitime juridicamente, o que reflete a simbologia de "existir" e "pertencer".

Lígia, 17 anos, é uma adolescente inserida na rede comercial de prostituição, envolvendo casas noturnas, como boates e saunas. Conforme apresentamos inicialmente, essa é uma população com a qual temos dificuldade de aproximação, pois o acesso é restrito pelos locais fechados, de caráter ilícito, nos quais se encontram.

A demanda, nesse caso, surge a partir da solicitação de ajuda da mãe de Lígia para o Conselho Tutelar, por meio do qual o Projeto Rotas é acionado. Contatos telefônicos são estabelecidos na tentativa de convidar Lígia e sua mãe para uma visita ao CAPS, porém não surtiram efeito. Como estratégia de acesso, a técnica de referência realizou uma visita domiciliar, acompanhada por um profissional do Centro de Saúde do bairro, que já tinha contato com a família, e, a partir daí, dá-se o início aos diálogos e à construção do vínculo. A composição familiar incluía Lígia, a mãe e um irmão.

Inicialmente muito arredia e com a saúde debilitada (baixo peso e problemas respiratórios), Lígia estava em casa, o que não era usual, parecendo ter interrompido os "programas" e as apresentações eróticas de dança, devido às más condições físicas. Em princípio, agiu como se não tivesse interesse em contato, mantendo um isolamento e certa frieza; diante da situação fez-se uma proposta à Lígia: estar com ela no espaço de sua casa, nas próximas semanas, para encaminhamento de demandas que a jovem apresentasse. Em meio às conversas aproximativas, buscou-se atentar para algum desejo ou necessidade expressos por Lígia, para que alguma atividade conjunta pudesse contribuir como veículo para a busca de um serviço de saúde, uma vez que ela necessitava de cuidados. 
Em certo momento, Lígia deixou claro que não possuía certidão de nascimento, pois a tinha perdido, nem documento de identidade, interessando-se em viabilizar essa documentação. Combinada essa atividade para o próximo encontro, Lígia, sua mãe e a técnica foram juntas a um cartório. No trajeto, muitos assuntos puderam ser abordados, além da possibilidade da técnica poder conhecer a dinâmica da relação de Lígia com sua mãe e com o espaço social, além de poder interagir com a jovem.

No momento em que Lígia recebeu da funcionária a certidão, ela afirma: "Pronto, não morro mais como indigente, agora tenho a minha identidade".

Constatando os conteúdos simbólicos desta fala, algumas reflexões puderam ser iniciadas: sobre o significado do existir, os medos a ele relacionados, enfim, sobre quem é Lígia. Abre-se uma brecha à subjetividade e desencadeia-se a possibilidade do compartilhar, do encontro com um outro, um estranho e, possivelmente, amedrontador. Além do significado simbólico que tem o documento de identidade, podese pensar no papel da técnica e na função da atividade em si: a retomada de condições básicas para uma existência como cidadã, com o direito de sentir-se diferenciada da massa social anônima, portanto, a atividade realizada a partir de uma demanda que é singular, abre a possibilidade, dentro de uma perspectiva contínua do acompanhamento terapêutico, de que Lígia tenha o direito de ser cuidada, o que fortalece algo ainda incipiente: o senso de identidade. Este parece ser précondição para o sentimento de pertencer a uma coletividade, como cidadã, e não como uma "indigente".

Essa condição se estabelece como um dos primeiros passos para a construção da capacidade de escolha: poder dizer, simplesmente, "não" ao universo das violências da contemporaneidade, em suas formas mais dissimuladas ou explícitas.

A realização da ação a partir da demanda inicial da jovem, ter sua documentação, desdobrou-se em outras atividades, como: atenção à saúde clínica, encaminhamento de questões de cultura e lazer, enfim, um acompanhamento mais amplo que possibilitou a retomada de outros laços sociais, refletindo o acesso a outros direitos.

O fazer conjunto, em favor da demanda do sujeito, possibilita a configuração de uma recolocação social, que favoreça a abertura de novas rotas, outros percursos de vida, vislumbrados com base na autonomia dos jovens.

As cenas relatadas destacam o universo de trabalho com essa população, sobre o qual se visava à promoção de ações de cuidado em saúde e direitos, operacionalizada através do acompanhamento terapêutico, em uma perspectiva norteadora, dada pela: redução de vulnerabilidades as quais essas crianças e jovens estavam expostos (ressignificar a rua, diminuir o uso de substâncias psicoativas, participar de atividades de convivência e de lazer); criação de fatores de proteção que diminuíssem as vulnerabilidades (do uso do preservativo ao retorno à escola); diminuição das exposições às violências cotidianas (da violência física à moral) e retomada e/ou fortalecimento da rede de suporte: laços com familiares e instituições.

Além disso, o diferencial almejado - que se constituía na incorporação do referencial dos direitos humanos como eixo condutor da intervenção - encontrou no AT um dispositivo interessante para sua operacionalização. Alguns fatores influentes na criação de contingências favoráveis ao exercício dos direitos básicos da infância e da juventude seriam: a criatividade das práticas; a ênfase na socialização e na ação a partir do desejo e, portanto, significativa a alguém; a ressignificação dos espaços e das ações sociais e, por fim, algo especial, o vínculo entre o profissional e a jovem construído nas relações extra-institucionais. Essas contingências parecem envolvidas em uma atmosfera de subjetividades, ou seja, um trabalho pretensamente mais abrangente do que outras propostas terapêuticas, que se dediquem a uma dimensão "mais intra-psíquica" da subjetividade.

Portanto, o acompanhamento terapêutico adaptou-se à mobilidade e ao trânsito dinâmico por ruas e espaços públicos, característica do dia-a-dia das meninas e meninos em situação de exploração sexual. Considerando que eles não se reconhecem em situação de vulnerabilidade social, dentro de um contexto sociocultural que não tem incorporado a juventude popular como sujeitos de direitos, projetos direcionados para esta população devem prever a disponibilidade metodológica de colocar suas práticas em cenários extra-institucionais. Ressalta-se a relevante perspectiva da construção de propostas em uma rede intersetorial, que desenvolva coletivamente, como princípio, o direito das crianças e dos adolescentes ao exercício de direitos. 


\section{Apontamentos das Limitações e Desafios nos Cenários da Intervenção}

O objetivo de compartilhar a experiência que está imbuída no presente relato requer que ressaltemos também algumas dificuldades e limitações, bem como algumas condições necessárias para maiores êxitos, uma vez que o referido projeto, pelo caráter piloto, propiciou aprendizagens.

0 perfil que se apresentou pouco presente nas intervenções do projeto foram os meninos e meninas, principalmente os meninos, que moravam ou trabalhavam em casas, espaços ou bairros de prostituição, devido à dificuldade em acessá-los, uma vez que não estavam em circulação nos espaços públicos, como esquinas, praças e ruas, encontrando-se de alguma forma institucionalizados; "escondidos" em locais privados. Envolvidos com redes comerciais e de serviços, como bares, boates, hotéis e saunas, além de redes de criminalidade, incluindo tráfico de drogas e de pessoas, ações resolutivas junto a esse perfil demandam ir muito além dos limites da atenção em saúde; requerem articulações prudentes junto à Secretaria de Segurança Pública (por meio das Delegacias de Infância e Juventude) e Poder Judiciário (por meio da Promotoria da Infância e Juventude), pelo potencial de risco de vida que oferecem.

Pontua-se a maior vulnerabilidade à exploração sexual e ao agravamento das violações de direitos e da exposição às situações de violência, nos casos da juventude envolvida com a prostituição confinada, cuja invisibilidade dificulta os processos de mobilização social rumo às medidas ( ou ações ) que revertam tais situações. Situação mais preocupante no caso da exploração sexual das jovens travestis e dos jovens "michês", cuja população, para que se realize um trabalho efetivo, requer variadas medidas, que vão desde a articulação com órgãos do âmbito Jurídico e da Segurança até, por exemplo, à incorporação da eqüidade de gênero e da diversidade sexual dentre os próprios profissionais que realizem o trabalho. Em alguns universos culturais somente é "permitida a entrada" mediante certa identificação com a população que os constrói e que é construída por esses universos.
Dentre as demais limitações, pontuamos, principalmente, a impossibilidade de avaliação de impactos em longo prazo na vida das adolescentes com as quais trabalhamos, devido ao reduzido período, de nove meses, dessa primeira etapa.

Outro fator incide sobre a pequena amostra estatística com a qual interviemos, que se relaciona com a baixa incidência de demanda espontânea nos serviços, apontando o pouco reconhecimento por parte dos sujeitos de sua condição de vulnerabilidade, demandando ações que vão ao encontro desta população, em um processo lento e gradual.

Ainda na perspectiva das limitações e dos desafios, os projetos têm dificuldade em operacionalizar a retomada e/ou o fortalecimento dos vínculos da juventude em situação de rua com a rede pessoal de suporte, o que se defronta com a insuficiência ou fragilidade das políticas públicas no trabalho com famílias pobres ${ }^{13}$. Para tanto, uma reflexão é necessária acerca da organização dos papéis centrais nas famílias pobres brasileiras, segundo as figuras do pai de família-provedor e da mãe-dona de casa (Sarti, 2003). Parece necessário discutirmos o esgarçamento e/ou rompimento dos vínculos das crianças e dos adolescentes com a rede familiar, o que caracteriza as experiências de rua, de modo a considerarmos que o cumprimento dos papéis muitas vezes é frustrado devido às condições externas e estruturais, o que geraria prejuízo ao cuidado dos filhos.

No universo dos 18 jovens que estiveram envolvidos no projeto, a presença da figura masculina na forma do pai biológico era bastante rara, as famílias eram em sua maioria monoparentais, chefiadas por mulheres, ou reconfiguradas com a presença do padrasto, ou ainda, famílias adotivas onde a(o) adolescente tinha sido pego para criar. Diante dessa "ausência" ou "substituição" do pai - nesse caso com o padrasto quase sempre na função de marido, mas não de responsável por compartilhar com a esposa as responsabilidades pelo cuidado dos filhos dela do relacionamento anterior - corre-se o risco de reforçar a idéia da mulher-mãe como a única responsável pelos "sucessos e fracassos" dos filhos, bem como pelo cuidado e pela garantia de seus direitos.

Essa realidade deve ser considerada e discutida em

13 Sobre Famílias e Políticas Públicas ver Acosta e Vitale, 2003. 
termos das ideologias e das metodologias dos projetos em questão para que eles não perpetuem injustiças de gênero. Somente pela análise das relações de gênero é possível compreender as desigualdades sociais no exercício do cuidado e construir a noção de cuidado no universo do discurso masculino, promovendo uma mudança revolucionária, quando o eixo do cuidado com os filhos começar a fazer parte da subjetividade masculina (Lyra e col., 2003).

Outros aspectos, não menos importantes, relacionam-se à esfera político-administrativa: as dificuldades na operacionalização do trabalho intersetorial (articulações entre as secretarias municipais); o diálogo por vezes áspero entre órgãos públicos, terceiro setor, conselhos representativos e sociedade civil e; finalmente, as transições entre os partidos políticos nas sucessivas gestões municipais e as interrupções abruptas, por vezes injustificadas, dos projetos desenvolvidos.

Projetos de caráter piloto-experimental, como o aqui apresentado, pela frágil institucionalização que os caracterizam, ocupam um lugar político de insegurança e fácil desmembramento. Por um lado, tais experiências produzem tecnologias sociais com potencial de ação, e, por outro lado, não são apreendidas no âmbito do desenvolvimento das intervenções, tendo dificuldade em se constituir como política pública. Assumindo um papel envolto numa esfera nostálgica, sem cumprir a proposição para a qual foram criados, sendo reduzidos a experiências pontuais fragmentadas e descontínuas.

O esforço inerente ao registro deste trabalho orienta-se pelas possíveis implicações para o campo das pesquisas e das políticas para a infância e a juventude em situação de vulnerabilidade, de modo que suscitem reflexões e práticas em outros locais que se dediquem a intervir diante das problemáticas da contemporaneidade. Essas exigem dos campos do saber, como a saúde coletiva, a saúde pública, a psicologia social comunitária, dentre outros, um esforço criativo e permanente.

Apontamos a discussão dos direitos humanos com meninos e meninas em situação de rua como tema abordado por outros autores (Panter-Brink, 2002), problematizando a relevância da dimensão do direito para a contextualização e intervenção com esta população.

Na área da exploração sexual há o desenvolvimen- to de outras experiências que discutem os aspectos positivos do uso do método do acompanhamento terapêutico como forma de abordagem a esta população (Franca, Teixeira e Goratti, 2002). 0 uso do AT propicia a aproximação dos meninos e meninas, criando o vínculo e mantendo-nos próximo, enfrentando uma das maiores dificuldades relatadas por projetos desta natureza: a adesão da população-alvo a qualquer proposição de abordagem. Utilizamos uma perspectiva de acompanhamento e responsabilização do técnico por aquela criança ou adolescente, o que faz com que esta relação se construa gradualmente e costure formas de se manter o trabalho.

Tem-se, portanto, a concretização de uma experiência que se direcionou a um caráter inovador no âmbito da política pública na medida em que possibilitou a inserção de novas metodologias de cuidado, diferentes daquelas já utilizadas pelos equipamentos sociais, pautando o trabalho territorial, o atendimento a um pequeno número de crianças e adolescentes, o encontro com o usuário, e não a espera dele, como princípios.

Certamente as limitações foram de grande impacto, como relatamos aqui, contudo é necessário que se criem espaços de experimentação de novas metodologias de abordagem, no âmbito público, para que se busquem alternativas de enfrentamento dos problemas contemporâneos.

Por fim, cabe aqui fazermos uma ressalva quanta à utilização dos conceitos e dos referenciais teóricos que utilizamos para "pensar" as ações no enfrentamento da prostituição/exploração sexual infanto-juvenil. Partimos de uma concepção sócio-histórica da realidade, na qual compreendemos que o campo social é de âmbito interdisciplinar e intersetorial, sendo que a saúde apresenta-se como uma das áreas que tem contribuições a partir de seu núcleo de intervenção, porém, isolada não possibilita a produção de resultados, pois não se trata de uma discussão unicamente do eixo saúde-doença. Esse comentário faz-se relevante para sublinharmos o aspecto de que não temos a intenção de criar "patologias" para o campo social; pelo contrário, a partir do conhecimento acumulado na saúde e a complexidade do fenômeno em questão, buscamos trazer contribuições para o campo e a integração de saberes e ações no escopo das políticas públicas. 


\section{Considerações Finais}

O Projeto Rotas Recriadas possibilitou a primeira intervenção diante da temática da exploração sexualprostituição infanto-juvenil no município de Campinas-SP, dentro de uma perspectiva intersetorial de ações da prevenção ao cuidado, que envolveram propostas do âmbito da educação, da cultura, da saúde, da justiça, do trabalho e da assistência social, compondo a rede de atendimento.

Pontua-se a relevância da disponibilidade para a construção de intervenções em rede e o olhar ampliado no que se refere aos atores sociais que se dediquem ao trabalho com crianças e adolescentes, em especial os em situação de exploração sexual. Segundo a lógica da articulação da rede, percebemos como as parcerias com os serviços especializados em cuidado e prevenção às DST/AIDS, ao uso abusivo de álcool e drogas, como as equipes de Redução de Danos e as ONGs que lutam pelo direito à diversidade de gênero e sexual (as ditas GLTTB ${ }^{14}$ ) são fundamentais, principalmente para o acesso à população confinada,

Diante da realidade socioeconômica com a qual convivemos, questionamo-nos se uma sociedade fundada no respeito aos direitos humanos, com recorte desta análise aos direitos da criança - tão debatidos e estabelecidos por convenções, leis e tratados nacionais e internacionais (ONU, 1959, 1989; Brasil, 1990) -, se confrontaria com fenômenos, como a exploração sexual infanto-juvenil, que denotam desigualdade social e precariedade nas relações de solidariedade para o reconhecimento do outro. Este se dá na dialética da identidade-alteridade e na valorização da singularidade da pessoa em situação peculiar de desenvolvimento, buscando o provimento de sua colocação efetiva, como sujeito, e a sustentabilidade do respeito a seus direitos.

Ressaltamos a necessária priorização das diferentes instâncias públicas pelo enfrentamento de temáticas complexas, como a exploração sexual infantojuvenil, prevendo, para tanto, a implantação de políticas públicas, destinações orçamentárias e diálogos permanentes com a sociedade civil para a criação de estratégias e metodologias condizentes com o fenômeno, almejando uma mudança cultural para a reversão do quadro estabelecido.
Para tanto, faz-se necessário pautar essas ações na perspectiva do direito, criando intervenções e práticas que se consolidem como ações públicas, devido à relevância social da temática, ocupando as agendas dos governos.

Acreditamos na função social da militância na área da Infância e Juventude, na luta pela diminuição das violações dos direitos e pela responsabilização das instâncias pertinentes, sejam elas da sociedade civil ou do poder público.

\section{Referências}

ACOSTA, A. R. e VITALE, M. A. F. Família: Redes, Laços e Políticas Públicas, IEE/PUCSP, São Paulo, 2003.

ALVES, J. A. L. Os direitos humanos como tema global. São Paulo: Perspectiva, 1994.

AYRES, J. R. C. M. et al. O conceito de vulnerabilidade e as práticas de saúde: novas perspectivas e desafios. In: CZERESNIA, D.; FREITAS, C. M. (Org.). Promoção da saúde: conceitos, reflexões, tendências. Rio de Janeiro: Fiocruz, 2003. p. 117-140.

BASAGLIA, F. (Org.). A instituição negada. Rio de Janeiro: Graal, 1985.

BERTOLOTE, J. M. Legislação relativa à saúde mental: revisão de algumas experiências internacionais. $R e$ vista de Saúde Pública, São Paulo, v. 29, n. 2, p.152-156, abr. 1995 .

BOBBIO, N. Dicionário de política. Brasília, DF: UnB, 2004 .

BRASIL. Estatuto da Criança e do Adolescente. São Paulo: Cortez, 1990.

CAMPOS, G. W. S. O método da roda: uma análise da gestão e co-gestão de coletivos. São Paulo: Hucitec, 2000.

CARVALHO, S. S. Acompanhamento terapêutico: que clínica é essa? São Paulo: Annablume, 2004.

EQUIPE DE ACOMPANHANTES TERAPÊUTICOS DO HOSPITAL-DIA A CASA (Org.). A rua como espaço clínico: acompanhamento terapêutico. São Paulo: Escuta, 1991.

14 Gays, lésbicas, transexuais, travestis e bissexuais. 
FÁBREGAS-MARTÍNEZ, A. I. Explorando a sexualidade do michê na cidade de Porto Alegre. In: BARBOSA, R. e al. (Org.). Interfaces: gênero, sexualidade e saúde reprodutiva. Campinas: Unicamp, 2002. p. 135-168.

FALEIROS, E. T. S. Repensando os conceitos de violência, abuso e exploração sexual de crianças e de adolescentes. Brasília, DF: CECRIA, 2000.

FRANCA, J. C.; TEIXEIRA, L. C.; GORGATTI, V. Estratégias de intervenção em situação de risco, extremo risco e exploração sexual. In: VASCONCELOS, M. G. O. M.; MALLAK, L. S. (Org.). Compreendendo a violência sexual em uma perspectiva multidisciplinar. Carapicuíba: Fundação Orsa Criança e Vida, 2002. p. 162-179.

FRANÇA JÚNIOR, I.; AYRES, J. R. C. M. Saúde pública e direitos humanos. In: ZÓBOLE, E.; FORTES, P. (Org.). Bioética e saúde pública. São Paulo: Loyola, 2003. p. 63-69.

GREGORI, M. F. Viração: experiência de meninos nas ruas. São Paulo: Companhia das Letras, 2000.

GRUSKIN, S.; TARANTOLA, D. Health and human rights. In: DETELS, R. et al. Oxford textbook of public health: the scope of public health. 4. ed. Oxford: Oxford University Press, 2001. p. 311- 335.

LEAL, M. L. P. Globalização e exploração sexual comercial de crianças e adolescentes. Rio de Janeiro: Save the Children, 2003.

LESCHER, A. D. Saúde mental e direitos humanos. Revista Brasileira de Psiquiatria, São Paulo, v. 24, n. 1, p. 3-4, mar. 2002.

Recebido em: 28/11/2005 Reapresentado em: 31/05/2006

Aprovado em: 19/09/2006
LYRA, J. e al. Homens e cuidado: uma outra família? In: VITALE, M. A. F.; ACOSTA, A. R. (Org.). Família: redes, laços e políticas públicas. São Paulo: IEE/PUCSP, 2003. p. 79-91.

ORGANIZAÇÕES DAS NAÇÕES UNIDAS - ONU. Convenção sobre os direitos da criança: 1989. Disponível em: <http://www.direitoshumanos.usp.br/counter/ Onu/Crianca/texto/texto_3.html> Acesso em: 18 maio 2005 .

ORGANIZAÇÕES DAS NAÇÕES UNIDAS - ONU. Declaração dos direitos da criança: 1959. Disponível em: <http://www.direitoshumanos.usp.br/counter/Onu/ Crianca/texto/texto_10.html>. Acesso em: 18 maio 2005.

PAIVA, V. Cenas sexuais, roteiros de gênero e sujeito sexual. In: BARBOSA, R.; PARKER, R. (Org.). Sexualidades pelo avesso: direitos, identidades e poder. Rio de Janeiro: Relume-Dumará, 1999. p. 249-269.

PANTER-BRICK, C. Street children, human rights and public health: a critique and future directions. Annual review of anthropology, Palo Alto, USA, v. 31, p. 147-171, May 2002.

PITANGUY, J. Violência de gênero e saúde: interseções. In: BERQUÓ, E. (Org.). Sexo e vida. Campinas: Unicamp, 2003. p. 319-337.

SARTI, C. A. A família como espelho: um estudo sobre a moral dos pobres. São Paulo: Cortez, 2003.

VASCONCELOS, M. G. O. M.; MALLAK, L. S. (Org.). Compreendendo a violência sexual em uma perspectiva multidisciplinar. Carapicuíba: Fundação Orsa Criança e Vida, 2002. 